\title{
Justification criteria for Inter-Basin Water Transfer Projects
}

\author{
Oussama Laassilia $^{1 *}$, Driss Ouazar ${ }^{1}$, Ahmed Bouziane $^{1}$, and Moulay Driss Hasnaoui ${ }^{2}$ \\ ${ }^{1}$ Hydraulic Systems Analysis Laboratory, Mohammadia School of Engineers, Mohammed V University in Rabat, Morocco \\ ${ }^{2}$ Water Resources Division, Water Department, Ministry of Equipment, Transport, Logistics and Water, Rabat, Morocco
}

\begin{abstract}
When implemented on a large scale, Interbasin Water Transfer (IBWT) projects are one of the most significant human interventions in natural environmental processes. Although water transfer might have considerable beneficial impacts, it produces inevitably other adverse effects on different levels. The present work aims to assess the phenomenon of IBWT to answer the question of whether such transfers are justified or not. To this end, this paper is first introduced by reviewing criteria proposed by some international organizations and epistemic communities for assessing IBWT. Then, a coherent set of IBWT evaluation criteria are proposed. Afterward, the authors have applied the chosen criteria to the North-South Water Transfer Project (NSWTP) in Morocco to provide a global assessment. The results show that the NSWTP, in its current version, is not justified. To remedy the negative sides of this project, the authors propose to limit the water transfer only between Sebou (donor) and Bouregreg (recipient), all in increasing the storage capacity of the recipient reservoir. On the other hand, studies related to the legal and institutional sides, and the ecological impacts are to be finalized.
\end{abstract}

\section{Introduction}

IBWT projects have been promoted for many centuries to alleviate the heterogeneous distribution of water resources. Proponents argue that they deliver socioeconomic development, enhance water security, and result in environmental benefits by alleviating ecological degradation in recipient basins suffering water shortage [1]. However, the implementation of these schemes is often contested, and the evaluation of their complex impacts is inadequate or hidden from full public scrutiny [1]. Therefore, the critical challenge is how to assess the implications of IBWT schemes effectively. For this purpose, this paper reviews the values and standards proposed to evaluate IBWT projects. It presents, first, the requirements proposed by the policy communities before examining the proposals of the epistemic communities. The paper then distils from these a coherent set of criteria for inter-basin water transfer schemes. Afterwards, those proposed criteria are applied to the NSWTP in Morocco.

\section{Overview of the IBWT justification criteria}

\subsection{Policy communities}

In 1978 the International Commission on Irrigation and Drainage proposed at its 10th Congress in Athens the following criteria for assessing such transfers: (1) Meet the present and future water demand of the exporting basin; (2) Reduce the water demand of the importing basin; (3) Minimize the impacts of the transfer on the exporting basin [2].

In 2000, the World Commission on Dams proposed five core values that need to be considered. These included participatory decision-making, equity, efficiency, sustainability, and accountability [3]. Public participation is an efficient means to ensure democratic decision-making.

The 1997 United Nation (UN) Convention on the Law of the Non-Navigational Uses of International Watercourses define two principles namely: (1) the right to use water resources equitably and reasonably; (2) The duty of riparian states is not to cause significant harm to other riparian states [4].

The 2000 European Water Framework Directive defines several criteria, including the precautionary principle, cost-effectiveness, the need to base decisions on sound science, the importance of public participation and providing the public with accurate information [5].

The Berlin Rules of Water Resources strongly embrace the concept of sustainable and integrated water resources management and the need to minimize environmental harm [6].

\subsection{Scientific communities}

Since the 1990s, many authors have defined and refined the concept of IBWT [7-8]. It has recognized the importance of sustainability and argues that: "Sustainable water resource systems are those designed and managed to fully contribute to the objectives of society, now and in the future, while maintaining their

\footnotetext{
* Corresponding author: oussama.laassilia90@gmail.com
} 
ecological, environmental and hydrological integrity" [4].

During a UNESCO-organized specialist workshop, held in Paris in 1999, Cox [9] has submitted the following criteria to assess IBWT projects: (1) the receiving area must face water scarcity that cannot be avoided by other reasonable measures; (2) water resources of the area of origin must be adequate; (3) substantial environmental damage should not occur in either area. (4) no substantial socio-cultural disruption should result in either area, including even emotional and religious motivations; (5) the benefits of the IBWT should be equitably shared between the area of delivery and the location of origin [9].

Gupta and Zaag [4] have proposed the following criteria to evaluate inter-basin transfer schemes in the context of integrated water resources management: (1) actual surplus and deficit; (2) sustainability; (3) good governance; (4) balance existing rights with needs (5) sound science including hydrological, ecological and socioeconomic analyses [4].

Smakhtin et al. [10] have suggested the five-point criteria of the United Nations Educational, Scientific and Cultural Organization as ideal world criteria for IBWTs to satisfy, viz: (1) reducing the recipient basin water demand and considering other alternatives; (2) water transfer must not limit the development of the donor basin; (3) environment degradation should be avoided in both basins unless compensation is assured; (4) socio-cultural impacts must be kept to minimal levels in both basins; (5) Share the net benefits from the water transfer equitably between the donor and the receiving basin [10].

Kibiiy and Ndambuki [11] have proposed a flexible approach to assess IBWTs, based on three basic requirements, namely, (1) justification of the need for water transfer; (2) demonstration of reducing the anticipated negative impacts; (3) demonstration of increasing the anticipated positive impacts [11].

More recently, Sinha et al. [12] have proposed the following criteria for evaluating the IBWT projects: (1) the donor basin must have surplus Water Availability (WA) after fulfilling all its present and future Water Demand (WD); (2) the recipient basin must have a water deficit after tapping all possibilities of WA within the basin; (3) the completed project must be supported by a multidisciplinary assessment intended to reduce adverse impacts, increase benefits, and demonstrate equitable distribution among basins; (4) analysis must use, where possible, data which is freely available within the public domain, and which should be made available for scrutiny [12].

\subsection{Proposed coherent set of criteria for the IBWT schemes evaluation}

A careful examination of the proposed values and standards shows some convergence towards concepts of sustainability and governance. The various listed principles dose not encompassing all the important values, and have some overlaps. In addition, few attempts tried to translate these general approaches into a formalized, practically applicable framework [12].
Given the number of potential schemes worldwide, it is, therefore, necessary to re-arrange those listed principles into a more coherent set of criteria, based on a comparative assessment of the different disciplinary; political, scientist and legal approaches. This section proposes the following integrated, holistic, and coherent set of criteria for evaluating IBWT justification:

- Real need

- Real present and future surplus in the donor basin;

- Real present and future deficit in the recipient basin;

- Testing other effective alternatives in the deficit basin.

- Governance and participatory approach

- Consistent legal and institutional framework;

- Harmony work between decision-makers, designers, scientists and affected population

- Sustainability

- Considering the aspects of sustainable development, social equity, economic profitability and environmental acceptability;

- Compelling environmental impact study to mitigate the negative impacts;

- Dynamic management and adaptability with climate change.

\section{Application of the proposed criteria to the NSWTP in Morocco}

\subsection{Overview of the NSWTP)}

Water resources in Morocco know very pronounced temporal and spatial disparities. The spatial ones are significant; three basins located north of the country, which cover only $7 \%$ of the total area, have $51 \%$ of the water resources. These areas have significant surpluses, and much of the water resources are lost at sea during wet seasons. On the other hand, the central basins, marked by critical industrial and agricultural poles with unprecedented population growth, have an increasingly negative water balance. Following this stressful situation, Morocco has adopted, since 2009, the idea of transferring surplus water from the northwest basins to the deficit basins in the centre of the country. The chosen design consists in moving water between six dam reservoirs, in service and projected, via $500 \mathrm{~km}$ of pipes, canals and galleries [13] (Figure 1).

\subsection{Assessment of the NSWTP in the light of the proposed criteria}

The objective of this assessment is to verify if the studies, related to this project, have considered the proposed criteria or not.

The first criterion concerns the demonstration of the surplus water of the donor basins and the real need of the recipient basins both in the present and future. The verification of this criterion was approached through the assessment of the flow series of different basins concerned by the NSWTP. Also, by the analysis of the present and future water demand in those basins. 


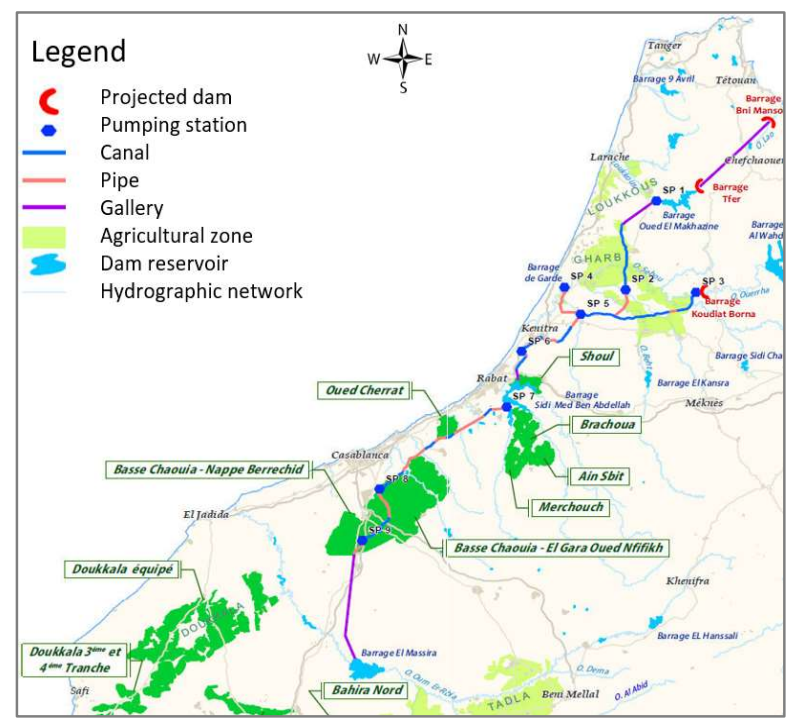

Fig. 1. Map of the planned NSWTP in Morocco (modified from [14]).

In this context, Figure 2 shows the flow series recorded in both the donors and the recipient basins between 1940 and 2010. This graph shows that those basins have the same climatic context; the wet years and the drought periods are generalized, with more pronounced variation in the basins of Sebou (donor) and Bouregreg (recipient). On the other hand, the polynomial trend analysis confirms the cyclical behaviour of the rains characterising those regions. In fact, the beginning of the flow series is marked by a wet cycle until 1979 that marks the inflection towards the dry cycle. The years 2009 and 2010, characterised by exceptional rainfall, reflect the beginning of a return to a wet cycle.

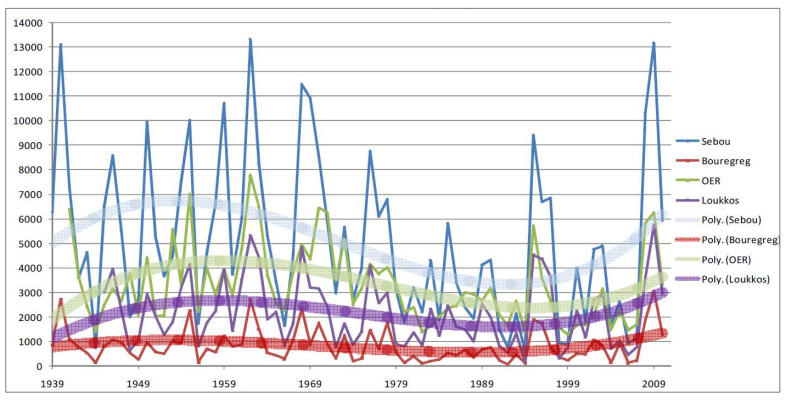

Fig. 2. Flow series of basins concerned by the NSWTP Polynomial trend [14].

The inflows series of the dams affected by the NSWTP confirms the hypothesis of the wet and dry period's succession (Figure 3). In addition, the studied basins' climate returns to the dry regime after the rainy years of 2008-2012. it is worth mentioning that the inflows of the Garde Sebou (GS) dam reservoir, located at the downstream end of the Sebou basin, are very important, and the peak flow during the wet periods is very pronounced. The inflows of the Massira dam are also immense, given the size of its watershed and the significant amount of rainfall it receives. Subsequently, the inflows of the Sidi Mohammed Ben Abdellah (SMBA) dam and the Makhazine dam are pretty similar due to their comparative climate contexts.

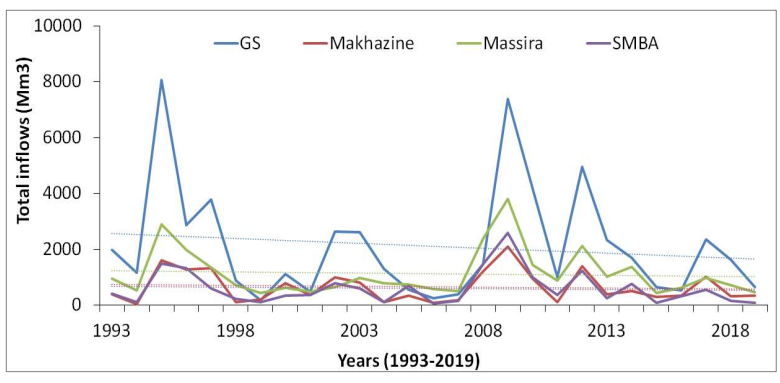

Fig. 3. Inflows of dams affected by the NSWTP (1990-2020).

Concerning the seasonal variation of the studied dams' inflows, figure 4 shows a clear distinction of two different periods; a wet season (from November to April) and a dry season (from May to October). The importance of the inflows varies from one dam to another following the analysis mentioned above about the inter-annual variation inflows. The Sebou basin (GS dam) experiences huge inflows with volumes of up to $5000 \mathrm{Mm}^{3}$ during the middle of the rainy period (January). The Massira dam inflows are also significant, and the peak of the maximum monthly inflows exceeds $1000 \mathrm{Mm}^{3}$ in March due to the late runoff generated following the snowmelt, characterising the upstream terrains of the Oum Errbia (OER) basin. The intraannual variation in the inflows of the Makhazine and the SMBA dams are also similar. However, the maximum SMBA inflows are in February and in December for the Makhazine dam.

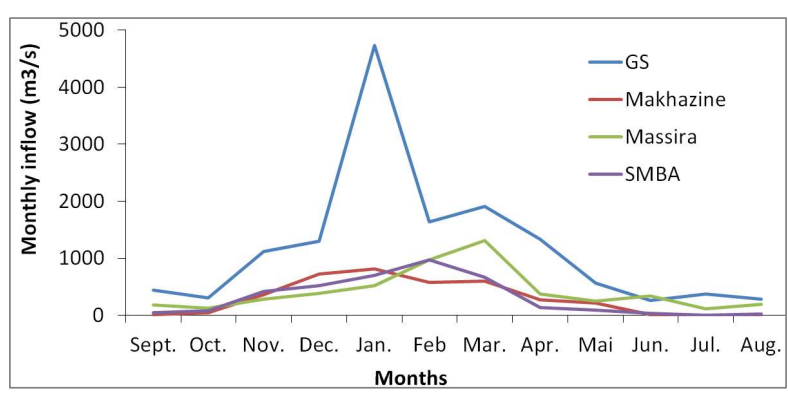

Fig. 4. Monthly inflows of the dams affected by the NSWTP.

The climate change impact has been analysed during the project's pre-feasibility studies, referring to the various hypotheses and models proposed by the Intergovernmental Panel on Climate Change (IPCC). The results estimate that the reduction rate of the inflows in the studied basins is about 20 to $25 \%$ by 2050 . However, the simulations carried out taking into account these variations have shown that climate change leads to lower the mean inflows but does not eliminate it during the excess years; it decreases the mean supplies but only slightly affects the transfer flow.

The water balances established in the Director Plan of the Water Resources Integrated Management, for different hydraulic basins concerned by the NSWTP in Morocco, indicate that the Sebou, Loukkos, and Laou basins are surplus. On the other hand, the OER and Bouregreg basins are in deficit. For the OER basin, although it has significant inflow volume, the deficit is generated by the substantial hydro-agricultural development carried out in the basin, exceeding its hydraulic capacity. 
It is also possible to judge the effectiveness of the NSWTP by the analysis of its impact on the annual volume of freshwater returned to the sea. Table 1 shows that this project could make it possible to supply the southern zones with a portion of the water currently returned to the sea in the north.

Table 1. Impact of the NSWTP on losses at sea.

\begin{tabular}{|c|c|c|c|}
\hline Watershed & $\begin{array}{c}\text { Inflow } \\
\left(\mathbf{M m}^{\mathbf{3}} / \mathbf{y r}\right)\end{array}$ & $\begin{array}{c}\text { Losses at } \\
\text { sea without } \\
\text { transfer } \\
\left(\mathbf{M m}^{\mathbf{3}} / \mathbf{y r}\right)\end{array}$ & $\begin{array}{c}\text { Losses at } \\
\text { sea with } \\
\text { transfer } \\
\left(\mathbf{M m}^{\mathbf{3}} / \mathbf{y r}\right)\end{array}$ \\
\hline Laou & 528 & 499 & 244 \\
\hline Makhazine & 974 & 617 & 493 \\
\hline Sebou & 4917 & 2506 & 2016 \\
\hline Total & 6419 & 3622 & 2753 \\
\hline
\end{tabular}

From this analysis, it turns out that transferring a part of excess water from the northern basins will make it possible to fill the chronic deficit in the central ones. However, it is possible to further optimize this project by reducing its schema and maximizing the transfer flow. Indeed, the volume returned to the sea from the Sebou basin $\left(40000 \mathrm{~km}^{2}\right)$ remains enormous even with the transfer $\left(2000 \mathrm{Mm}^{3} / \mathrm{yr}\right)$. This reality might limit the transfer of water only from this basin without recourse to the other northern basins. On the other hand, the estimated water surplus in the Laou basin may be the subject of a transfer to the western areas, which also has a chronic deficit. Concerning the excess water in the Makhazine basin $\left(1800 \mathrm{~km}^{2}\right)$, which are already limited and vulnerable to climate change impacts, the authors recommend to use them for the development of the agricultural sector. In addition, this basin is located in a mountainous allowing to improve their storage capacity through the construction of new dams, and therefore ensuring the availability of water during shortage periods (As in 1981-1985, 1999-2002, and 2014-2016). As for the OER basin $\left(35000 \mathrm{~km}^{2}\right)$, it has very significant water resources. Thus, several programs aiming economizing the irrigation water by switching from gravity to drip mode, and the development of unconventional methods, such as desalination and rainwater collection, are drawn up and planned in the DPWRIM. In addition, the auto- satisfaction of the Bouregreg basin will allow to no longer use the water transferred from the OER basin, estimated at 120 $\mathrm{Mm}^{3} / \mathrm{yr}$. For this purpose, the transfer of water to the OER basin is not convincing. The proposed scheme also saves an enormous cost of the hydraulic structures works relating to this project, extending over a $440 \mathrm{~km}$ line, with several pumping stations. Therefore, transferring the maximum part of excess water from the Sebou to satisfy the water need of the Bouregreg basin appears to be the best choice.

It is important to note that this project could be more effective if the storage capacity of the recipient basin is increased. Indeed, from the management history analysis of the SMBA dam reservoir, it turned out that the filling rate of this dam usually exceeds $80 \%$, even after its first heightening in 2009, and the dam often spills during the floods periods. Therefore, the transferred volume would be much less compared to the enormous amount of water that is likely to be transferred, especially in the winter season. In addition, the succession of dry years makes the entire system vulnerable, especially the future irrigation water demand in the Bouregreg basin. Following this observation, topographical and geological examination of the current dam site revealed the possibility of further heightening this dam by around $25 \mathrm{~m}$ which allow gaining approximately $2500 \mathrm{Mm}^{3}$ more of the stored volume. Regarding the socio-economic impact of this heightening, the Bouregreg valley is developing in a mountainous context, limiting the extent of the landowners' terrains that would be flooded by the future reservoir.

In the light of all the above, the proposed scheme of the NSWTP consists of transferring the maximum excess water from the GS dam (Sebou Basin) to the SMBA dam (Bouregreg basin), after its heightening, through $53 \mathrm{~km}$ of galleries, pipes, and canals (Figure 5).

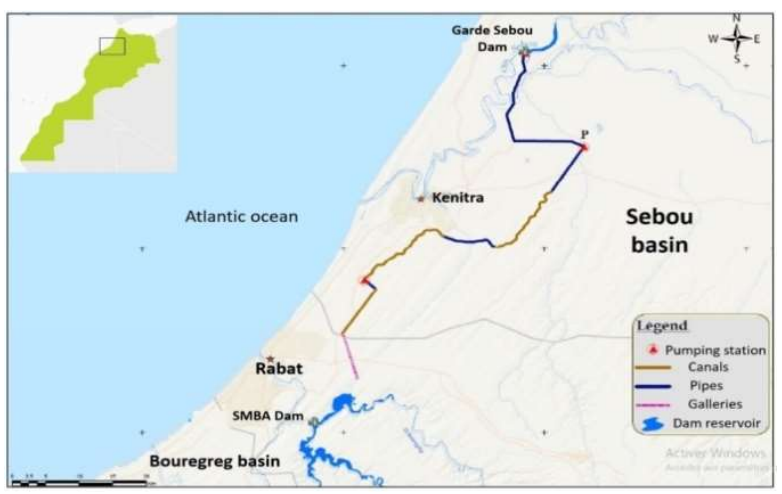

Fig. 5. Proposed scheme of the NSWTP in Morocco.

The second criterion concerns governance and participatory decision-making. As has been frequently observed, problems concerning water can mainly be due to failures in governance. Thus, the legal and institutional arsenal provides a consistent basis for the good management of IBWT projects. In Morocco, the water sector is managed by law 36-15 that sets the rules for integrated, decentralised, and participatory management of water resources to guarantee the right of citizens to access water. This law also aims to establish rules and mechanisms for unconventional water resources, including wastewater treatment, seawater desalination, and water transfer between regions. As the NSWTP is under study, the designation of an institutional framework destined to the management of this project is not yet done. However, the already existing legal and institutional framework makes it possible to find an effective means for the best control of this project. In its proposed version, the NSWTP will only take place between two neighbouring watersheds. Although the direction of this kind of water transfer system is not new in Morocco. However, the authors recommended to create a joint commission including representatives of the concerned basin, and the government institution in charge of water for the 
coordination, monitoring, and implementation of this project, both during studies and operation.

At present, the technical aspects of the project have been widely discussed between decision-makers and designers through several studies and projects. However, this project has not been the subject of political or public debate due to the absence of the information shared by decision-makers. To this end, the authors recommended to notify the population, especially those concerned by this project, to take into account their opinions and proposals. On the other hand, the scientist and researchers' contribution is modest. Although it is essential to verify and complete the engineering studies, it gives a significant added value to the scheme design and the optimal management of this project under the climate change impact, as was done by El Moçayd et al. [15]

Considering the third criterion, namely sustainability, the studied project could be sustainable as long as the economic, social, and environmental aspects are all respected. Indeed, the project's sustainability is intimately linked to the best integration in its natural and social context. The studies carried out concluded that the NSWTP environmental impact is estimated as a medium to low [16]. However, the authors recommend to complete those studies by assessing the impact of the projected structures on the lands' stability and the soil quality, given that $80 \%$ of the lands crossed are farmlands and forests. The studies also assert that there is no apparent risk of the water salinisation from the dam reservoirs in the Sebou basin. Also, the wastewater resulting from domestic, industrial and agricultural activities are globally treated before their ejection in the Sebou river tributaries. Thus, the transferred water is of good quality [16]. Nevertheless, to ensure the quality of the transferable water, and therefore the sustainability of the project, it is recommended to:

- Update the inventory of pollution sources and the evolution of water quality in the Sebou basin.

- Study the risks of accidental pollution and the management mechanisms of the structures.

- Set up an environmental monitoring program for the water quality along with the project infrastructures.

Regarding the NSWTP social impact, it mainly concerns the relocation of the population due to the setting up of the water transfer structures. According to the NSWTP official version, the total number of dwellings directly affected is 210 , i.e., approximately 1100 persons. The future reservoir of the Beni Mansour dam will drown a total area of 897 ha. The agroforestry area occupies about 484 ha or $54 \%$. The population to be displaced is about 1200 people. Concerning the Kodiat Borna dam, the lands that will be flooded mainly concern agricultural fields of about 705 ha, located on the right bank of the Ouergha River. In addition, the project will cross a diversified landscape over a length of $500 \mathrm{~km}$ with a width of $5 \mathrm{~m}$ for pipes and $10 \mathrm{~m}$ for canals, and several intersections with railways line, roads, and highways. According to the proposed schemes, this impact will be significantly reduced. The line of the new route extends just over $53 \mathrm{~km}$, without crossing transport routes or populated areas. As for the SMBA heightening impact, the future reservoir would flood some forest terrains, mountainous lands, few agricultural fields, and some kilometres of regional road sections. Nevertheless, the authors recommend to study sufficiently the implementation impact of structures related to the NSWTP to minimise their influence on the existing infrastructure on the one hand, and on the other hand, preparing a plan for awareness and support of the concerned population to adapt to the new project and minimise the change in their way of life, especially the farmers.

\section{Conclusion}

This article reviews some of the values and criteria that have been proposed, by the policy organisations and the scientific communities, to assess inter-basins water transfers. Then, a coherent set of criteria has been developed based on three main principles, namely real need, governance, and sustainability. By applying these criteria to the NSWTP in Morocco, it turns out that the transfer of a part of excess water from the northern basins will make it possible to fill the chronic deficit in the central basins. However, the authors recommend to further optimise this project by reducing its schema and maximising the transfer flow. The proposed scheme consists of transferring the maximum excess water from the Garde Sebou (GS) dam (Sebou Basin) to the SMBA dam (Bouregreg basin), with the heightening of the latter. As for the second criterion, which concerns governance, the designation of an institutional framework dedicated to the management of this project is not yet done. Thus, it is recommended to create a joint commission including representatives from the concerned basins for the coordination, monitoring, and implementation of this project both during studies and operation. The authors also recommend to encourage scientific researches about the NSWTP and invite stakeholders to provide the information necessary to carry out these studies. Considering the third criterion, namely sustainability, the impact studies of the NSWTP on the environment evaluated the overall ecological impact of the project as a medium to low. According to the proposed schemes, this impact will be significantly reduced. The climate change studies show that the inflows of the studied basins will be reduced by 20 to $25 \%$ by 2050 . Nevertheless, the simulations carried out, taking into account these variations, have shown that climate change leads to lower the mean inflows but does not eliminate it during the excess years; it decreases the mean supplies but only slightly affects the transfer flow.

\section{References}

1. W. Zhuang, Envir. Sci. Pollution Res. 23(13), 12867-12879 (2016)

2. K. Rahman, Interbasin water transfer: Bangladesh perspective. Proceedings of the International Workshop in Hydrology N²8. Paris, 81-95(1999)

3. World Commission on Dams (WCD), Report of the WCD. Earthscan, London (2000)

4. J. Gupta, P. Zaag, Phys. Chem. Earth. 33, 28-40 (2008) 
5. EU, Framework for Community Action in the Field of Water Policy. Directive 2000/60/EC (2000)

6. International Law Association, Berlin Rules of Water Resources, Berlin (2004)

7. R. Koudstaal, F. Rijsberman, H.H.G. Savenije, Natural Resources Forum 16 (4), 277-290 (1992)

8. ASCE, Division of Water Resource Planning and Management. Task Committee for Sustainability Criteria (1998)

9. W.E. Cox, determining when interbasin water management is justified. Proceedings of the International Workshop, UNESCO, Paris, 173-184 (1999)

10. V. Smakhtin, N. Gamage, L. Bharati, Hydrol. Envir. 79-106 (2009)

11. J. Kibiiy, J. Ndambuki, Physics and Chemistry of the Earth 89-90, 121-126 (2015)

12. P. Sinha, E. Rollason, L.J. Bracken, J. Wainwright, M. Reaney, Sci. Total Envir. 721, 137646 (2020)

13. O. Laassilia, D. Ouazar, A. Bouziane, M.D. Hasnaoui, Particle Swarm Optimization applied to Multi-Reservoir Operating Policy in Inter-Basin Water Transfer System, 5th International Conference on Optimization and Applications, Kenitra, Morocco, 1-5 (2019)

14. Hydraulic Works Directorate (HWD), Study of the water transfer schemes from Loukkos, Laou and Sebou basins to the South (2014)

15. N. El Moçayd, S. Kang, A.B.E Elfatih, Hydrol. Earth Syst. Sci. 24, 1467-1483 (2020)

16. Water Research and Planning Directorate (WRPD), Environmental impact study of the N-S Water Transfer Project. (2012) 